\title{
T-type Calcium Channel Blocker ABT-639
}

National Cancer Institute

\section{Source}

National Cancer Institute. T-type Calcium Channel Blocker ABT-639. NCI Thesaurus.

Code C118315.

An orally bioavailable, CaV3.2 T-type calcium channel blocker with potential antihyperalgesic activity. Upon oral administration, ABT-639 selectively binds to and blocks the CaV3.2 isoform of the low voltage-gated T-type calcium channels located in peripheral sensory neurons. This prevents the influx of calcium ions into the cell upon membrane depolarization. The inhibition of both neuronal hyperexcitability and firing of nociceptive, peripheral sensory neurons induces an anti-nociceptive effect. The expression of the CaV3.2 T-type channels plays a key role in nociceptive and neuropathic pain. 